\title{
Study on Conventional and Rheological Properties of Corn Stalk Bioasphalt/PPA Composite Modified Asphalt
}

\author{
Fuhai Wang, ${ }^{1}$ Tuo Huang $\mathbb{D}^{2},{ }^{2}$ Gongfeng Xin, ${ }^{1}$ Minghao $M u,{ }^{1}$ and Quanjun Shen ${ }^{1}$ \\ ${ }^{1}$ Shandong Hi-Speed Group Innovation Research Institute, Jinan 250098, China \\ ${ }^{2}$ National Engineering Laboratory of Highway Maintenance Technology, School of Traffic and Transportation Engineering, \\ Changsha University of Science \& Technology, Changsha 410114, China \\ Correspondence should be addressed to Tuo Huang; ht@csust.edu.cn
}

Received 21 July 2021; Revised 17 August 2021; Accepted 4 October 2021; Published 25 October 2021

Academic Editor: Han-Yong Jeon

Copyright (c) 2021 Fuhai Wang et al. This is an open access article distributed under the Creative Commons Attribution License, which permits unrestricted use, distribution, and reproduction in any medium, provided the original work is properly cited.

\begin{abstract}
As a new type of pavement material, bioasphalt has received more and more attention. However, the high-temperature behavior of bioasphalt is poor after blending with asphalt binder. In order to solve this problem and facilitate the waste utilization and resource conservation, the corn stalk bioasphalt/PPA composite modified asphalt was proposed. The conventional performance tests and rheological tests were conducted to evaluate high-temperature and low-temperature behavior. Fourier transform infrared reflection (FTIR) test was undertaken to analyze the mechanism of modified asphalt. The results indicated that blended asphalt penetration and ductility gradually decrease with the PPA content increasing. The softening point and viscosity of the modified asphalt increased, which led to an improvement of blended asphalt's rigidity. The PPA increased the rutting index of corn stalk bioasphalt/PPA composite modified asphalt. However, bioasphalt had a negative effect on its high-temperature performance. The corn stalk bioasphalt/PPA composite modified asphalt could meet the specification requirement at $-18^{\circ} \mathrm{C}$ considering the creep rate and stiffness modulus, indicating it had outstanding crack resistance. When the PPA and bioasphalt respect to the weight of neat asphalt were $6 \%-8 \%$ and $10 \%-16 \%$, respectively, the corn stalk bioasphalt/PPA composite modified asphalt performance was optimal. However, shear time and shear rate merely affected the proposed modified asphalt performance. The bioasphalt did not affect the chemical structure of asphalt. However, $\mathrm{PPA}$ generated new functional groups ( $\mathrm{P}-\mathrm{O}$ single bond, phosphate $(\mathrm{RO})_{3} \mathrm{P}=\mathrm{O}$, and $\mathrm{P}=\mathrm{O}$ double bond) causing a chemical modification in the asphalt binder. This study can provide a basis for applying bioasphalt, making road engineering more economical and environmentally friendly.
\end{abstract}

\section{Introduction}

Since the start of the 21 st century, the need for asphalt has sharply increased with the vigorous development of worldwide transportation construction. In the context of the global pandemic, the demand for crude oil has suddenly decreased, leading to increased pressure on the supply and demand of asphalt. Moreover, asphalt is a petroleum processing product, which means it is a nonrenewable resource [1]. Hence, finding an alternative to mitigate this problem has become a hotspot in current research works. Bioasphalt can be obtained from biomass materials through pyrolysis technology. It has attracted more attention from scholars because of its characteristics of being extremely cheap and environmentally friendly [2]. Assuming that bioasphalt can entirely or partially replace petroleum asphalt, the former material can reduce the dependence on the latter material, making road construction greener, environmentally friendly, and more economically viable.

The biomass resources are abundant in China. Bioasphalt is a by-product of the plant refining process. The bioasphalt performance is similar to that of petroleum asphalt. In this study, the waste product obtained during the refining process of corn stalks was selected as bioasphalt. Furthermore, bioasphalt reacts with polyurethane and rubber, but there are few studies on directly blending it with neat asphalt [3-6]. After the regeneration of aged asphalt with bioasphalt, the asphalt's stiffness modulus decreases, and the creep rate increases. Bioasphalt can positively affect the low-temperature behavior and fatigue performance of the recycled asphalt mixture. 
However, it harms the high-temperature behavior [5, 7-9]. The creep rate of the rubber-modified asphalt has been increased by using bioasphalt. Bioasphalt improves and increases the low-temperature and rutting index of neat asphalt, respectively $[6,10]$. Adding bioasphalt to the neat asphalt decreases its viscosity and high-temperature behavior. Besides, dynamic stability, splitting strength, and compressive resilience modulus of asphalt mixture will decrease, but the low-temperature behavior increases [11-13]. In summary, the application of corn stalks bioasphalt has not been efficiently studied yet. The low-temperature behavior of bioasphalt has been improved, but the high-temperature behavior needs to be further enhanced.

In order to expand the application of bioasphalt and enhance the high-temperature behavior of blended asphalt, the most effective method has been polymer modification, such as SBS or SBR [14]. SBS modified asphalt has been the most widely used because of its excellent performance, but its price is high [15]. Polyphosphoric acid (PPA) has been successfully applied because of its lower cost and superior compatibility with neat asphalt, and it shows a remarkable improvement in the high-temperature behavior of asphalt [16-18]. After using PPA modified asphalt, the colloidal structure and system change, the resin decreases, and the asphaltene content gradually rises [19]. It enhances the asphalt high-temperature behavior and improves storage stability [20]. After using PPA modified asphalt, the rutting index can be increased so that the pavement has positive resistance to permanent deformation [18, 21]. PPA can improve the cohesiveness, elasticity, and rutting resistance of SBR modified asphalt. SBR modified asphalt has higher toughness and recovery rate. The asphalt high-temperature behavior is prominent when the PPA content increases [17]. PPA can significantly enhance the creep recovery of rubbermodified asphalt. The temperature scanning test results have demonstrated that PPA can increase the rutting index of rubber asphalt [22, 23]. However, PPA harms the water stability of the bioasphalt mixture [24]. Many studies have manifested that PPA can significantly enhance the hightemperature behavior of different types of asphalt.

In summary, if the bioasphalt is blended with neat asphalt and then modified with PPA, on the one hand, bioasphalt may partially replace the content of petroleum asphalt, and, on the other hand, PPA will enhance the hightemperature behavior of the blended asphalt. The bioasphalt will produce economic benefits and make road engineering greener and environmentally friendly. This study will adopt an orthogonal test design. The bioasphalt contents will be set at $10 \%, 12 \%, 14 \%$, or $16 \%$ and PPA contents will be $2 \%, 4 \%$, $6 \%$, or $8 \%$. Furthermore, the shear time and shear rate will be considered for preparing corn stalk bioasphalt/PPA composite modified asphalt. In this study, the conventional performance and rheological tests to evaluate the modified asphalt behavior and determine its best preparation plan will be undertaken. Finally, FTIR test will be conducted to analyze the mechanism of modified asphalt. This research work provides a theoretical basis for promoting the practical application of corn stalk bioasphalt/PPA composite modified asphalt.

\section{Raw Materials and Test Methods}

2.1. Raw Materials. The neat asphalt from Chongqing Huiming Company was utilized in this study. Its technical indexes are shown in Table 1. Bioasphalt was the product of the corn stalks refining process, and it was a dark brown viscous liquid; its technical indicators are displayed in $\mathrm{Ta}$ ble 2. Polyphosphoric acid (PPA) was obtained from Henan Hui-Fa Chemical Company. The technical indicators are shown in Table 3.

\subsection{Preparation of Corn Stalk Bioasphalt/PPA Composite} Modified Asphalt. The experimental scheme was determined by orthogonal design. The factors and levels are described in Table 4 . Then, the corn stalk bioasphalt/PPA composite modified asphalt was prepared using the FM300 high-speed shear apparatus. First, the neat asphalt and bioasphalt were preheated in a bake-out furnace at $135^{\circ} \mathrm{C}$ for 2 hours. Second, the neat asphalt was blended with bioasphalt. The bioasphalt contents were $10 \%, 12 \%, 14 \%$, and $16 \%$ of the neat asphalt mass, and the shear rate was $1500 \mathrm{r} / \mathrm{min}$ for 20 minutes. Finally, corn stalk bioasphalt/PPA composite modified asphalt was prepared by adding a specific content of PPA according to Table 5. At the same time, different shear times and shear rates were utilized to prepare corn stalk bioasphalt/PPA composite modified asphalt.

2.3. Test Method. According to the specification (JTG E202011), the penetration, ductility, softening point, and viscosity tests of 16 groups of corn stalk bioasphalt/PPA composite modified asphalt were implemented. The dynamic shear rheometer (DSR) test was used for temperature scanning. The temperature scanning range was $40^{\circ} \mathrm{C}-88^{\circ} \mathrm{C}$. The low-temperature behavior of corn stalk bioasphalt/PPA composite modified asphalt was tested by using the bending beam rheometer (BBR) test. The rolling thin-film oven aging (RTFO-aging) test and pressurized aging vessel (PAV) test of asphalt were carried out before the BBR test. Finally, FTIR analyzed the functional groups of neat asphalt, bioasphalt, blended asphalt, PPA modified neat asphalt, and corn stalk bioasphalt/PPA composite modified asphalt. The preparation and test process are shown in Figure 1.

\section{Analysis and Discussion of Test Results}

3.1. Conventional Physical Properties. According to the specification (JTG E20-2011), the 16 groups of corn stalk bioasphalt/PPA composite modified asphalts were tested for conventional physical properties. The results are displayed in Table 6. Furthermore, the visual and variance analysis of conventional physical properties are shown in Tables 7 and 8.

3.1.1. Penetration. According to Table 7, the influence order of the factors on the penetration is as follows: PPA content $>$ bioasphalt content $>$ shear time $>$ shear rate. As shown in Table 8, PPA content has a particularly significant effect on penetration. The bioasphalt content impact on 
TABle 1: Technical index of neat asphalt.

\begin{tabular}{lcc}
\hline Index & Test results & Technical requirements \\
\hline Penetration $\left(25^{\circ} \mathrm{C}\right) / 0.1 \mathrm{~mm}$ & 62.3 & $60-80$ \\
Ductility $\left(15^{\circ} \mathrm{C}\right), \mathrm{cm}$ & 147 & $\geq 100$ \\
Softening point, ${ }^{\circ} \mathrm{C}$ & 46.8 & $\geq 46$ \\
Flash point, ${ }^{\circ} \mathrm{C}$ & 316 & $\geq 260$ \\
Wax content, \% & 1.56 & $\leq 2.2$ \\
\hline
\end{tabular}

TABLE 2: Technical indicators of bioasphalt.

\begin{tabular}{lc}
\hline Index & Test results \\
\hline $\mathrm{PH}$ & 2.6 \\
Density, g/cm & \\
Trichloroethylene solubility, \% & 0.97 \\
\end{tabular}

TABle 3: Technical indicators of PPA.

\begin{tabular}{lc}
\hline Index & Test results \\
\hline Content $\left(\mathrm{P}_{2} \mathrm{O}_{5}\right), \%$ & 80.36 \\
Density $\left(25^{\circ} \mathrm{C}\right), \mathrm{g} / \mathrm{cm}^{3}$ & 2.1 \\
Boiling point, ${ }^{\circ} \mathrm{C}$ & 532 \\
Sulfide $(\mathrm{Cl}), \%$ & $<0.001$ \\
\hline
\end{tabular}

TABle 4: Orthogonal test table of factor level.

\begin{tabular}{lccccc}
\hline Variables & Unit & \multicolumn{4}{c}{ Coded and actual factor } \\
\hline PPA content & $\%$ & 2 & 4 & 6 & 8 \\
Bioasphalt content & $\%$ & 10 & 12 & 14 & 16 \\
Shear time & $\mathrm{min}$ & 20 & 30 & 40 & 50 \\
Shear rate & $\mathrm{r} / \mathrm{min}$ & 1000 & 2000 & 3000 & 4000 \\
\hline
\end{tabular}

penetration is higher than those of the shear time and shear rate. Shear time and shear rate do not affect penetration. Figure 2 reveals that the penetration of corn stalk bioasphalt/ PPA composite modified asphalt gradually decreases with the increase of PPA content from $2 \%$ to $6 \%$. However, penetration does not significantly change when the PPA contents are $6 \%$ and $8 \%$. When PPA content is $8 \%$, the penetration is the smallest. The average penetration is 64.8 when the PPA content is $8 \%$, and the decrease ratio is $4 \%$ compared with neat asphalt. Penetration gradually decreases with PPA content increasing. This fact shows that PPA has an evident hardening influence on the corn stalk bioasphalt/ PPA composite modified asphalt. According to Figure 2, the penetration gradually increases with the bioasphalt content increasing. It indicates that the bioasphalt would have a specific softening effect. In particular, the penetration obviously increases with the increase of bioasphalt. Compared with the neat asphalt, when PPA content is $2 \%$ and bioasphalt contents are $10 \%, 12 \%, 14 \%$, and $16 \%$, the penetration increases by $102.6 \%, 118.5 \%, 140.1 \%$, and $193.6 \%$, respectively. Bio-oil is a kind of light material, and, during high-temperature preparation, the unstable light material volatilizes because of the aging phenomenon. However, the constant part is modified with the neat asphalt, which causes the asphalt to soften at ambient temperature and increase the penetration [25].
3.1.2. Softening Point. According to Table 7, the influence order of the factors on the softening point is as follows: PPA content $>$ bioasphalt content $>$ shear rate $>$ shear time. As shown in Table 8, the PPA content had a particular effect on the softening point. Shear time and shear rate merely affect the softening point. Figure 3 shows that the softening point would increase with PPA content changing from $2 \%$ to $8 \%$. It indicates that the PPA can enhance the high-temperature behavior and temperature sensitivity. When the PPA content is $2 \%, 4 \%, 6 \%$, or $8 \%$, the average softening point is $44.35^{\circ} \mathrm{C}, 59.9^{\circ} \mathrm{C}, 68.13^{\circ} \mathrm{C}$, or $72.83^{\circ} \mathrm{C}$, respectively, and the enhanced ratio compared with the neat asphalt is $-5.24 \%$, $27.99 \%, 45.57 \%$, or $55.61 \%$, respectively. The softening point gradually decreases with the bioasphalt content increasing, indicating that bioasphalt would harm the high-temperature behavior. When the PPA content is $8 \%$ and bioasphalt content is $10 \%, 12 \% 14 \%$, or $16 \%$, the softening point is $78.6^{\circ} \mathrm{C}, 75.2^{\circ} \mathrm{C}, 70.6^{\circ} \mathrm{C}$, or $66.9^{\circ} \mathrm{C}$, respectively, and, compared with the neat asphalt, the enhanced ratio is $67.95 \%$, $60.68 \%, 50.85 \%$, or $42.95 \%$, respectively. The softening point is enhanced because PPA changes the asphalt components: the resin continues to decrease, and the asphaltene content gradually increases, which increases its stiffness and hardness $[6,26,27]$. Due to the reconstitution of colloidal structure in asphalt, the softening point of asphalt has been significantly improved.

3.1.3. Ductility. The ductility was tested at $5^{\circ} \mathrm{C}$ and the results are shown in Figure 4. The neat asphalt ductility is $168 \mathrm{~mm}$ at $5^{\circ} \mathrm{C}$. According to Table 7, the influence order of the factors on the ductility is as follows: bioasphalt content $>$ PPA content $>$ shear time $>$ shear rate. According to Table 8, the PPA and bioasphalt content effects on ductility are significant. However, the shear time and shear rate have no effect on it. It can be observed that the ductility is maximum when the PPA content is $2 \%$ and the bioasphalt content is $16 \%$. Ductility does not significantly change when the PPA content is in the range of $6 \%-8 \%$. When the PPA content is $6 \%$ and bioasphalt content is $10 \%, 12 \%, 14 \%$, or $16 \%$, the ductility is $287.2 \mathrm{~mm}, 346.2 \mathrm{~mm}, 374.7 \mathrm{~mm}$, or $432.2 \mathrm{~mm}$, respectively, and, compared with the neat asphalt, the enhanced ratio is $70.95 \%, 106.07 \%, 123.04 \%$, or $157.26 \%$, respectively. The ductility gradually increases with bioasphalt content increases. It reveals that plasticity increases. However, the ductility results show a descending trend with the rise of PPA content. It indicates that PPA decreases the plasticity of the asphalt binder. Compared with neat asphalt, the ductility of the modified asphalt dramatically rises. A previous research work has shown that bioasphalt increases the fracture energy of asphalt and significantly enhances ductility [28]. At the same time, the bio-oil made the asphalt have enough light components at high temperature and correspondingly increases the proportion of oil in the asphalt, so the ductility increases [25].

3.1.4. Viscosity. Asphalt with greater viscosity will produce less shear deformation under load. It has better elastic recovery performance and less residual permanent 
TABle 5: Orthogonal test table.

\begin{tabular}{lcccc}
\hline Number & PPA content/\% & Bioasphalt content $/ \%$ & Shear time/min & Shear rate/r/min \\
\hline 1 & 2 & 10 & 20 & 1000 \\
2 & 2 & 12 & 40 & 2000 \\
3 & 2 & 14 & 50 & 3000 \\
4 & 2 & 16 & 30 & 4000 \\
5 & 4 & 10 & 20 & 3000 \\
6 & 4 & 12 & 50 & 4000 \\
7 & 4 & 14 & 40 & 1000 \\
8 & 4 & 16 & 40 & 4000 \\
9 & 6 & 10 & 50 & 3000 \\
10 & 6 & 12 & 20 & 2000 \\
11 & 6 & 14 & 30 & 1000 \\
12 & 6 & 16 & 50 & 2000 \\
13 & 8 & 10 & 40 & 1000 \\
14 & 8 & 12 & 30 & 4000 \\
16 & 8 & 14 & 20 & 3000 \\
\hline
\end{tabular}

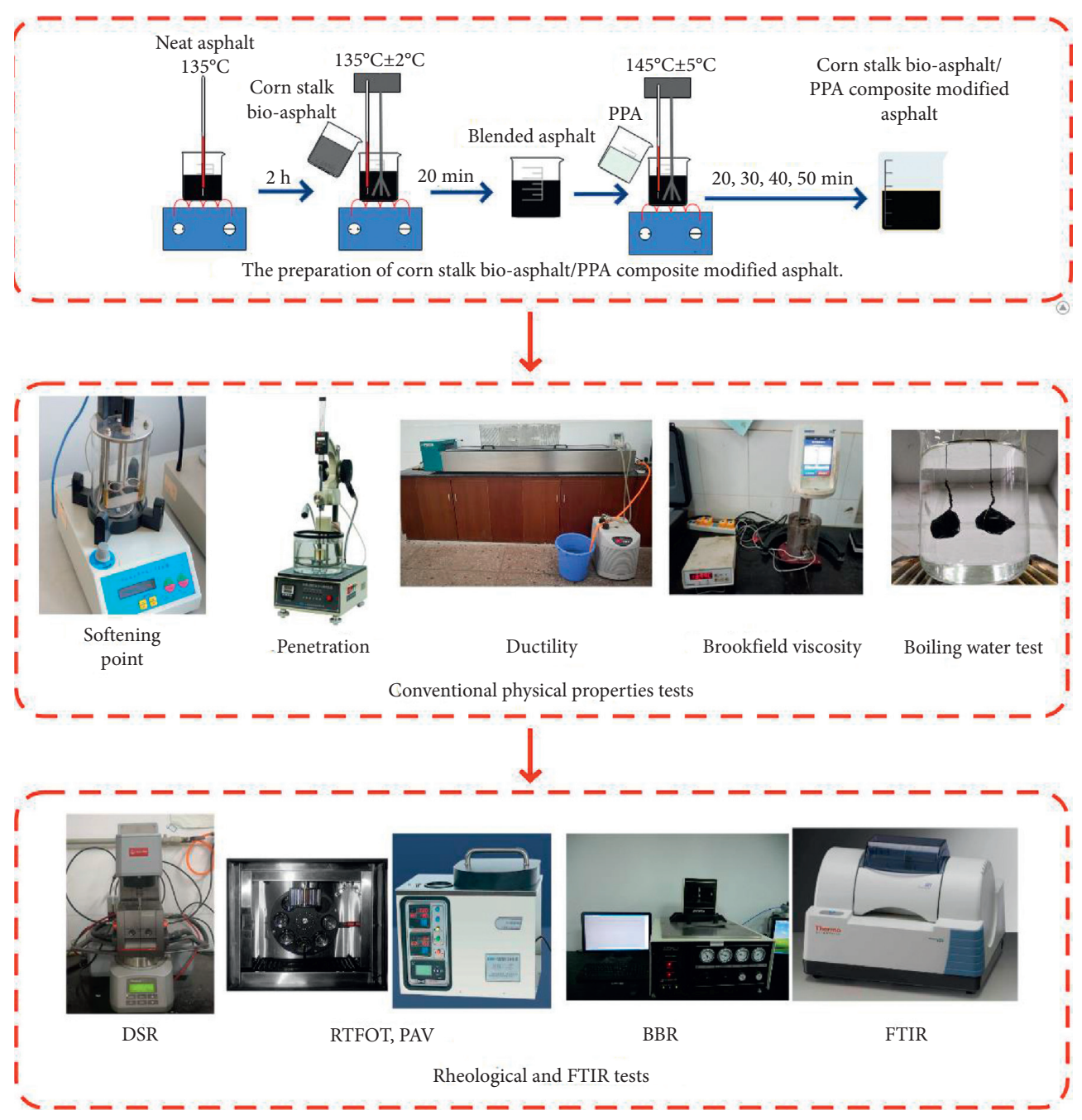

Figure 1: Preparation and test process of corn stalk bioasphalt/PPA composite modified asphalt.

deformation so that the asphalt mixture has a better hightemperature behavior. The viscosity test was performed at $135^{\circ} \mathrm{C}$. The test results are depicted in Figure 5. The viscosity of neat asphalt is $476 \mathrm{MPa} \cdot \mathrm{S}$ at $135^{\circ} \mathrm{C}$. According to Table 7 , the influence order of the factors on the viscosity is as follows: PPA content $>$ bioasphalt content $>$ shear 
TAвLe 6: Conventional physical properties.

\begin{tabular}{lcccc}
\hline No. & Penetration/0.1 mm & Softening point $/{ }^{\circ} \mathrm{C}$ & Ductility $/ \mathrm{mm}$ & Viscosity $\left(135^{\circ} \mathrm{C}\right) / \mathrm{MPa} \cdot \mathrm{S}$ \\
\hline 1 & 126.2 & 52.2 & 396.2 & 375.5 \\
2 & 136.1 & 46.1 & 430.8 & 316 \\
3 & 149.6 & 42.3 & 541.7 & 279 \\
4 & 182.9 & 36.8 & 590.8 & 226 \\
5 & 70.3 & 65.4 & 326.3 & 589.7 \\
6 & 80.6 & 60.5 & 352.7 & 423 \\
7 & 95.6 & 60.1 & 403.3 & 402.7 \\
8 & 116.8 & 53.6 & 468.6 & 359 \\
9 & 61.3 & 73.2 & 287.2 & 801 \\
10 & 63.8 & 68.6 & 346.2 & 716 \\
11 & 65.2 & 66.1 & 374.7 & 698.7 \\
12 & 74.2 & 64.6 & 432.2 & 584.3 \\
13 & 59.3 & 78.6 & 279.4 & 1031 \\
14 & 62.2 & 75.2 & 328.1 & 952 \\
15 & 67.3 & 70.6 & 356.7 & 62.5 \\
16 & 70.4 & 66.9 & 410.3 & 624 \\
\hline
\end{tabular}

TABLE 7: Visual analysis of conventional physical properties.

\begin{tabular}{|c|c|c|c|c|c|}
\hline Index & Factor & PPA & Bioasphalt & Shear time & Shear rate \\
\hline \multirow{5}{*}{ Penetration } & Average value 1 & 148.7 & 79.28 & 85.6 & 89.55 \\
\hline & Average value 2 & 90.83 & 85.68 & 86.98 & 94.35 \\
\hline & Average value 3 & 66.13 & 94.43 & 97.48 & 88.53 \\
\hline & Average value 4 & 64.8 & 111.08 & 100.4 & 98.03 \\
\hline & Range & 83.9 & 31.8 & 14.8 & 9.5 \\
\hline \multirow{5}{*}{ Softening point } & Average value 1 & 44.35 & 67.35 & 61.43 & 63.03 \\
\hline & Average value 2 & 59.9 & 62.6 & 61.68 & 61.1 \\
\hline & Average value 3 & 68.13 & 59.78 & 61.08 & 60.8 \\
\hline & Average value 4 & 72.83 & 55.48 & 61.03 & 60.28 \\
\hline & Range & 28.48 & 11.88 & 0.65 & 2.75 \\
\hline \multirow{5}{*}{ Ductility } & Average value 1 & 489.88 & 322.28 & 383.48 & 389.95 \\
\hline & Average value 2 & 387.73 & 364.45 & 386.5 & 388.38 \\
\hline & Average value 3 & 360.08 & 419.1 & 406.4 & 406.13 \\
\hline & Average value 4 & 343.63 & 475.48 & 404.93 & 396.85 \\
\hline & Range & 146.25 & 153.2 & 22.93 & 17.75 \\
\hline \multirow{5}{*}{ Viscosity } & Average value 1 & 299.13 & 699.3 & 530.3 & 578.63 \\
\hline & Average value 2 & 443.6 & 601.75 & 560.63 & 601.18 \\
\hline & Average value 3 & 700 & 533.23 & 597.75 & 552.18 \\
\hline & Average value 4 & 839.88 & 448.33 & 593.93 & 550.63 \\
\hline & Range & 540.75 & 250.98 & 67.45 & 50.55 \\
\hline
\end{tabular}

TABLE 8: Analysis of variance of conventional physical properties.

\begin{tabular}{|c|c|c|c|c|c|c|c|}
\hline Index & Factor & Deviation sum of squares & Degrees of freedom & Mean-squared & $F$-value & $P$ value & Significance \\
\hline \multirow{4}{*}{ Penetration } & PPA & 18496.5 & 3 & 6165.5 & 22.92 & 0.001 & **** \\
\hline & Bioasphalt & 2280.67 & 3 & 760.22 & 0.47 & 0.71 & \\
\hline & Shear time & 660.98 & 3 & 220.32 & 0.13 & 0.94 & \\
\hline & Shear rate & 233.6 & 3 & 77.87 & 0.043 & 0.99 & \\
\hline \multirow{4}{*}{ Softening point } & PPA & 1874.68 & 3 & 624.89 & 23.6 & 0.001 & **** \\
\hline & Bioasphalt & 298.2 & 3 & 99.4 & 0.63 & 0.61 & \\
\hline & Shear time & 1.13 & 3 & 0.38 & 0.002 & 1.0 & \\
\hline & Shear rate & 17.27 & 3 & 5.76 & 0.032 & 0.99 & \\
\hline \multirow{4}{*}{ Ductility } & PPA & 51651.66 & 3 & 17217.22 & 3.64 & 0.045 & ** \\
\hline & Bioasphalt & 53115.37 & 3 & 17705.12 & 3.84 & 0.039 & $* *$ \\
\hline & Shear time & 1732.48 & 3 & 577.49 & 0.065 & 0.98 & \\
\hline & Shear rate & 784.64 & 3 & 261.55 & 0.029 & 0.99 & \\
\hline \multirow{4}{*}{ Viscosity } & PPA & 716324.21 & 3 & 238774.74 & 16.89 & 0.001 & **** \\
\hline & Bioasphalt & 135528.28 & 3 & 45176.09 & 0.72 & 0.56 & \\
\hline & Shear time & 12019.04 & 3 & 4006.35 & 0.055 & 0.98 & \\
\hline & Shear rate & 6950.81 & 3 & 2316.94 & 0.032 & 0.99 & \\
\hline
\end{tabular}

${ }^{*} P \leq 0.1$ is generally significant. ${ }^{* *} P \leq 0.05$ is significant. ${ }^{* * *} P \leq 0.001$ is particularly significant. 

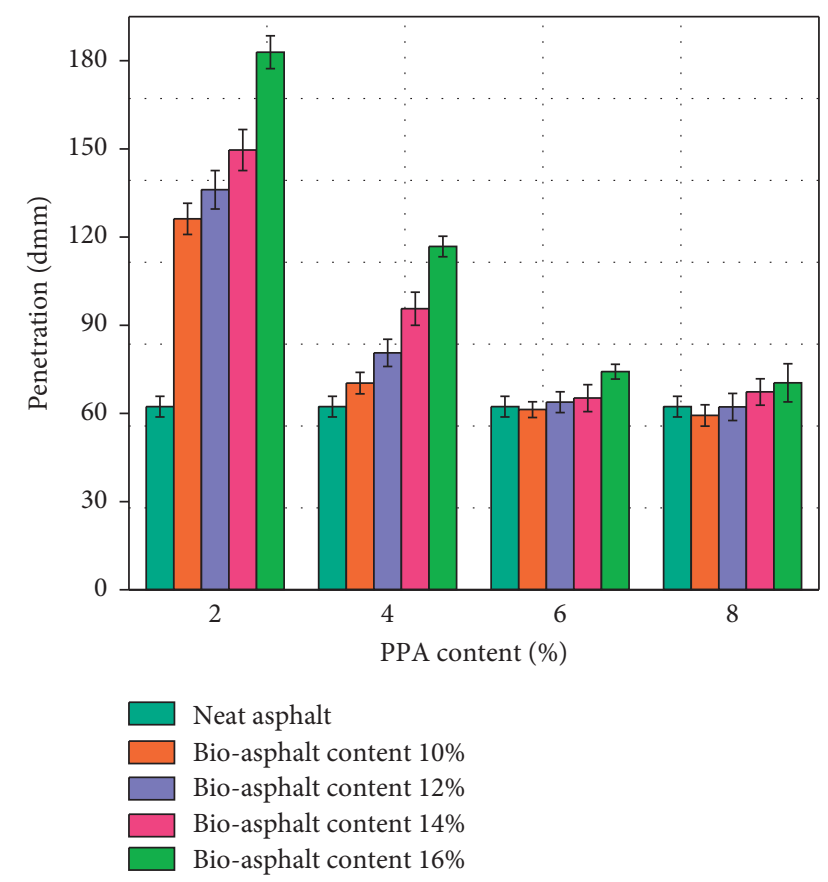

Figure 2: Penetration.

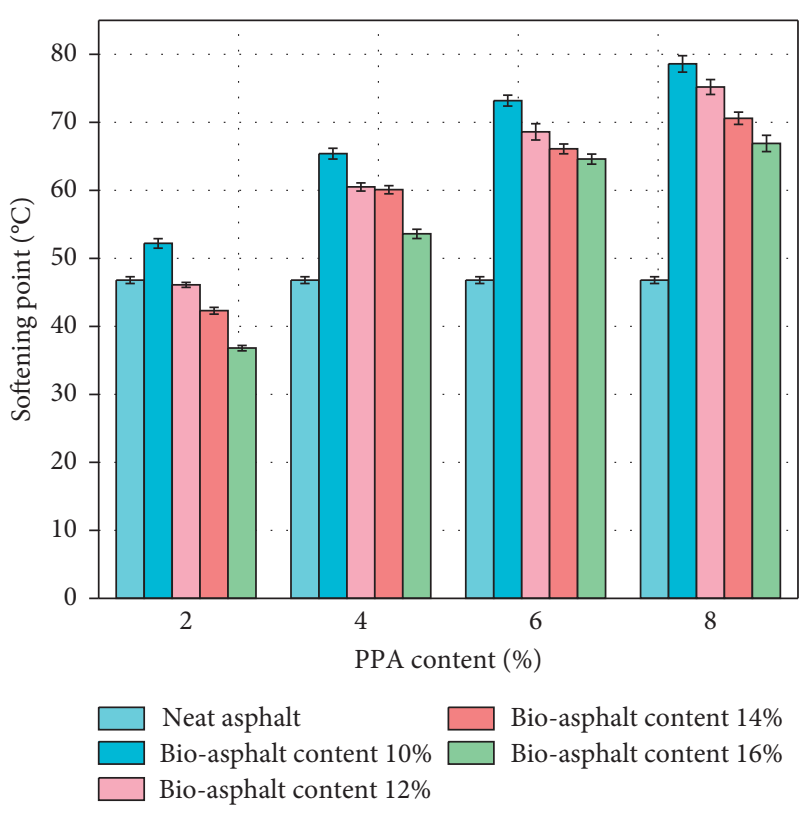

FIGURE 3: Softening point.

time $>$ shear rate. From Table 8, it can be concluded that PPA content has a particularly significant effect on viscosity. As shown in Figure 5, the viscosity of the modified asphalt is better than that of the neat asphalt when PPA content is higher than $6 \%$. Obviously, the viscosity gradually increases when the PPA content increases. When the PPA content is $8 \%$ and the bioasphalt content is $10 \%, 12 \%, 14 \%$, or $16 \%$, the viscosity is $1031 \mathrm{MPa} \cdot \mathrm{S}, \quad 952 \mathrm{MPa} \cdot \mathrm{S}, \quad 752.5 \mathrm{MPa} \cdot \mathrm{S}$, or $624 \mathrm{MPa} \cdot \mathrm{S}$, respectively, and the enhanced ratio is $116.6 \%$, $100 \%, 58.09 \%$, or $31.09 \%$, respectively. The increase in the viscosity will improve the high-temperature behavior of the asphalt mixture [29].
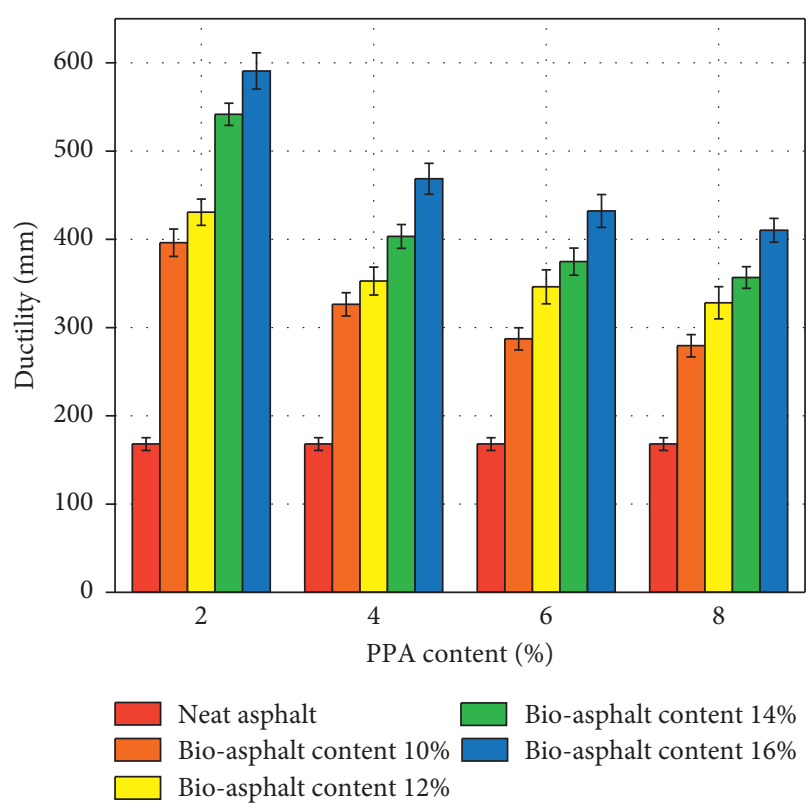

Figure 4: Ductility.

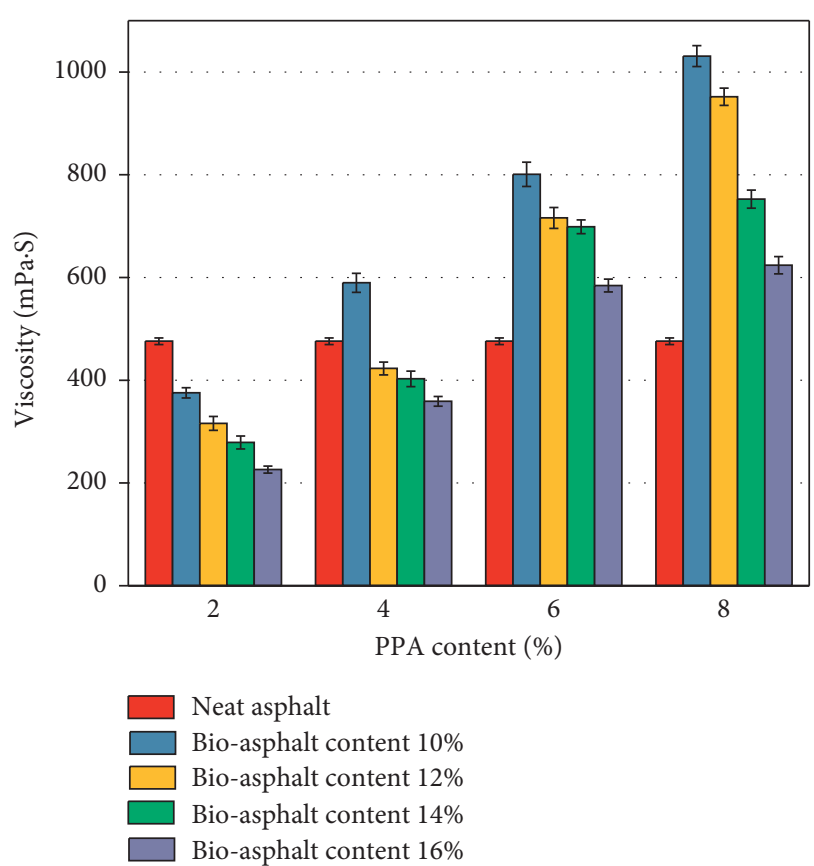

Figure 5: Viscosity.

3.2. Rheological Properties. This study carried out the DSR and BBR tests to evaluate the rheological behavior of the asphalt binder. In summer, the asphalt pavement is exposed to sunlight, which increases the upper layer's temperature. The actual temperature is about $60^{\circ} \mathrm{C}$ [30]. This study focuses on the rutting index at $60^{\circ} \mathrm{C}$ to evaluate high-temperature behavior. After RTFO-aging and PAV tests, the corn stalk bioasphalt/PPA composite modified asphalt was placed into asphalt trabeculae and subjected to $\mathrm{BBR}$ test at $-18^{\circ} \mathrm{C}$. Furthermore, the creep rate and stiffness modulus were used as low-temperature evaluation indicators. The results of the rheological properties are shown in Table 9. 
TABle 9: Rheological properties.

\begin{tabular}{lccccc}
\hline No. & $G^{*}\left(60^{\circ} \mathrm{C}\right) \mathrm{KPa}$ & $\delta\left(60^{\circ} \mathrm{C}\right)$ & $G^{*} / \sin \delta / \mathrm{KPa}\left(60^{\circ} \mathrm{C}\right)$ & Creep rate $\left(-18^{\circ} \mathrm{C}\right)$ & Stiffness modulus/MPa $\left(-18^{\circ} \mathrm{C}\right)$ \\
\hline 1 & 1.72 & 79.4 & 1.75 & 0.48 & 40.3 \\
2 & 1.33 & 81.36 & 1.35 & 0.47 & 32.4 \\
3 & 1.13 & 82.7 & 1.14 & 0.48 & 31.9 \\
4 & 0.84 & 85.46 & 0.84 & 0.49 & 31.5 \\
5 & 4.75 & 68.23 & 5.11 & 0.33 & 44.6 \\
6 & 3.15 & 68.63 & 3.38 & 0.41 & 41.3 \\
7 & 3.07 & 71.96 & 3.23 & 0.44 & 32.9 \\
8 & 2.07 & 66.75 & 2.25 & 0.43 & 32.8 \\
9 & 7.06 & 60.88 & 8.08 & 0.35 & 62.5 \\
10 & 4.94 & 62.78 & 5.55 & 0.35 & 51.7 \\
11 & 3.80 & 65.57 & 4.17 & 0.34 & 42.5 \\
12 & 3.36 & 66.09 & 3.67 & 0.35 & 38.2 \\
13 & 9.16 & 57.82 & 10.82 & 0.34 & 86 \\
14 & 6.46 & 60.8 & 7.4 & 0.31 & 58.9 \\
15 & 5.72 & 65.32 & 6.3 & 0.32 & 49.7 \\
16 & 4.55 & 62.81 & 5.11 & 0.38 & 43.6 \\
\hline
\end{tabular}

3.2.1. Temperature Scanning. Asphalt resistance to shear deformation could be reflected by the complex shear modulus $[31,32]$. The complex shear modulus $\left(60^{\circ} \mathrm{C}\right)$ of the neat asphalt was $2.82 \mathrm{KPa}$. As shown in Figure 6, when PPA content is $8 \%$ and the content of bioasphalt is $10 \%, 12 \%$, $14 \%$, or $16 \%$, the complex shear modulus is $9.16 \mathrm{KPa}$, $6.46 \mathrm{KPa}, 5.72 \mathrm{KPa}$, or $4.55 \mathrm{KPa}$, respectively. The increase ratio was $224.75 \%, 129.06 \%, 103 \%$, or $61.18 \%$, respectively. Besides, the complex shear modulus gradually decreases with the bio-oil content increasing. However, the complex shear modulus gradually increases with PPA content increasing. When bioasphalt content is $10 \%$ and the content of PPA is $2 \%, 4 \%, 6 \%$, or $8 \%$, the complex shear modulus is $1.72 \mathrm{KPa}, 4.75 \mathrm{KPa}, 7.06 \mathrm{KPa}$, or $9.16 \mathrm{KPa}$, respectively. The increase ratio is $-39 \%, 68.28 \%, 150.31 \%$, or $224.75 \%$, respectively. It indicates that PPA can significantly enhance the high-temperature behavior of asphalt.

The phase angle reflects the asphalt's elasticity (recoverable part) to viscosity (unrecoverable part). It indicates that the asphalt is transformed from elastic to viscous. When the phase angle decreases, the modulus's less dense component is under load in the high-temperature state. The asphalt has excellent deformation resistance when the unrecoverable part was smaller. The phase angle of neat asphalt is $86.86^{\circ}$. Figure 7 shows that the phase angle is significantly lower than that of neat asphalt. When PPA content is $8 \%$ and the content of bioasphalt is $10 \%, 12 \%, 14 \%$, or $16 \%$, the phase angles were $57.82^{\circ}, 60.8^{\circ}, 65.32^{\circ}$, or $62.81^{\circ}$, respectively. The reduction ratio is $33.43 \%, 30 \%, 24.8 \%$, or $27.69 \%$, respectively. The phase angle decrease is due to the fact that PPA made the corn stalk bioasphalt/PPA composite modified asphalt more elastic. The phase angle decrease shows that it increases the asphalt's rebound rate under load, thereby improving the asphalt's high-temperature stability $[33,34]$.

Table 10 and Table 11 illustrate the visual and variance analysis of the rutting index $\left(G^{*} / \sin \delta\right)$ at $60^{\circ} \mathrm{C}$. According to Table 10, the influence order of the factors on the rutting index $\left(60^{\circ} \mathrm{C}\right)$ is as follows: PPA content $>$ bioasphalt content $>$ shear time $>$ shear rate. As shown in Table 11, the

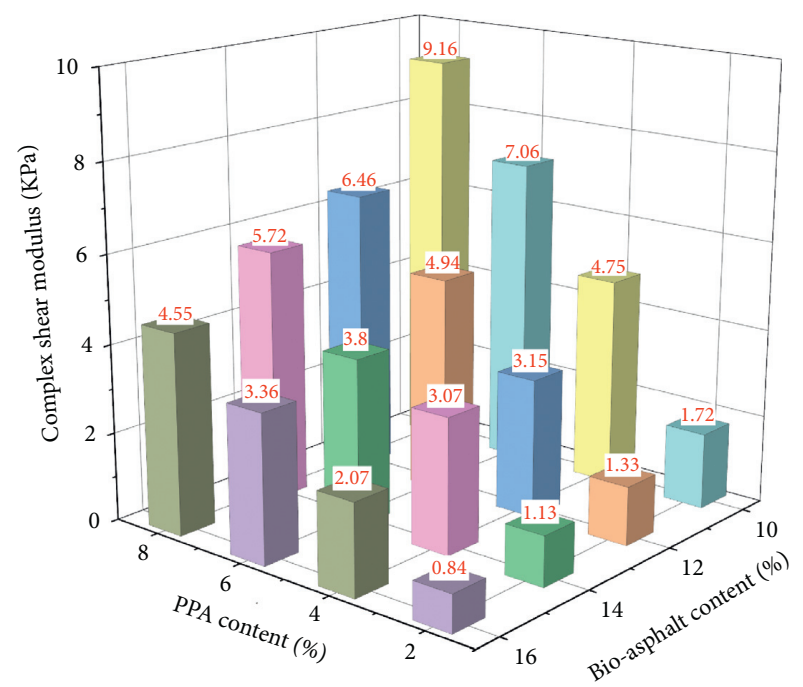

Figure 6: Complex shear modulus $\left(60^{\circ} \mathrm{C}\right)$.

impact of PPA content on this parameter is significant. The implication of bioasphalt content on the rutting index is significantly higher than that of the other two factors.

As shown in Figure 8, the rutting index $\left(60^{\circ} \mathrm{C}\right)$ gradually increases with the PPA content increasing. The rutting index has a significant increase when PPA content is higher than $6 \%$. When the PPA content is $6 \%$ and the content of bioasphalt is $10 \%, 12 \%, 14 \%$, or $16 \%$, the rutting index $\left(60^{\circ} \mathrm{C}\right)$ is 8.08 $\mathrm{KPa}$, 5.55 KPa, 4.17 KPa, or $3.67 \mathrm{KPa}$, respectively. The increase ratio is $186.52 \%, 96.81 \%, 47.84 \%$, or $30.14 \%$, respectively. When bioasphalt content is $10 \%$ and the PPA content is $2 \%, 4 \%, 6 \%$, or $8 \%$, the rutting index $\left(60^{\circ} \mathrm{C}\right)$ is $1.75 \mathrm{KPa}, 5.11 \mathrm{KPa}, 8.08 \mathrm{KPa}$, or $10.82 \mathrm{KPa}$, respectively. The increase ratio is $-37.94 \%, 81.21 \%, 186.52 \%$, or $283.69 \%$, respectively. It indicates that PPA can enhance the hightemperature behavior of the modified asphalt. It happens because of the asphalt composition changes: the asphaltene increases, and the colloid decreases. The new colloidal structure made the high-temperature behavior significantly improved [16, 22, 35]. 


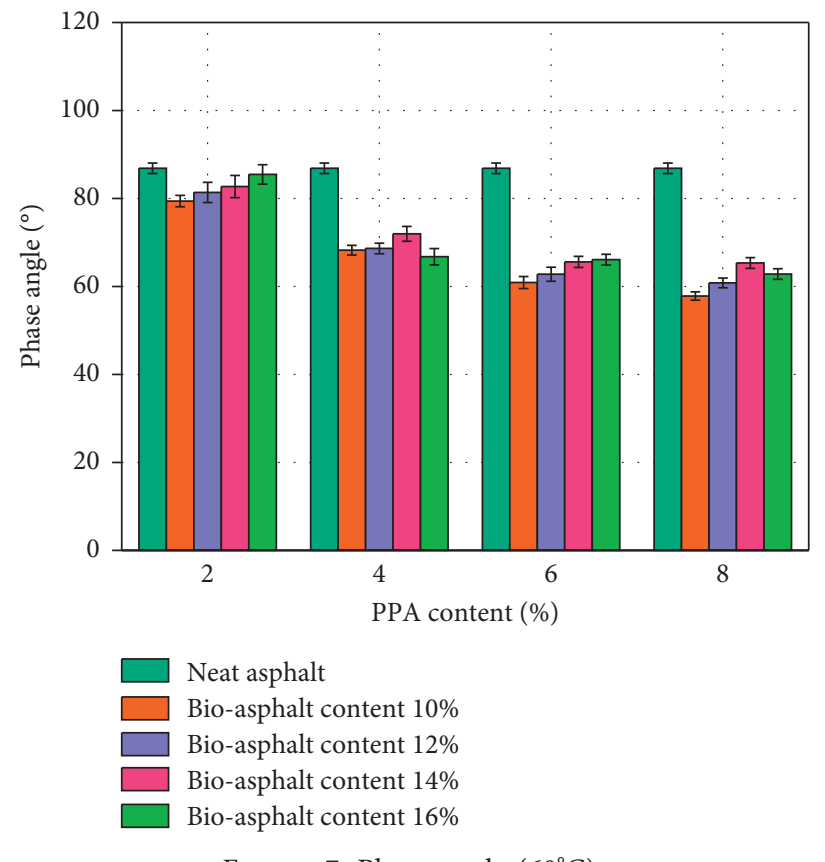

Figure 7: Phase angle $\left(60^{\circ} \mathrm{C}\right)$.

TABLe 10: Visual analysis of rutting index $\left(60^{\circ} \mathrm{C}\right)$.

\begin{tabular}{lcccc}
\hline Factor & PPA & Bioasphalt & Shear time & Shear rate \\
\hline Average value 1 & 1.27 & 6.44 & 3.60 & 4.01 \\
Average value 2 & 3.49 & 4.42 & 4.11 & 4.72 \\
Average value 3 & 5.37 & 3.71 & 5.11 & 4.23 \\
Average value 4 & 7.41 & 2.97 & 1.51 & 4.65 \\
Range & 6.14 & 3.47 & 0.64 \\
\hline
\end{tabular}

TABLe 11: Analysis of variance of rutting index $\left(60^{\circ} \mathrm{C}\right)$.

\begin{tabular}{|c|c|c|c|c|c|c|}
\hline Factor & Deviation sum of squares & Degrees of freedom & Mean-squared & $F$-value & $P$ value & Significance \\
\hline $\mathrm{PPA}$ & 82.40 & 3 & 27.47 & 9.54 & 0.002 & ** \\
\hline Bioasphalt & 26.76 & 3 & 8.92 & 1.19 & 0.356 & \\
\hline Shear time & 5.3 & 3 & 1.77 & 0.19 & 0.90 & \\
\hline Shear rate & 1.21 & 3 & 0.40 & 0.042 & 0.99 & \\
\hline
\end{tabular}

${ }^{*} P \leq 0.1$ is generally significant. ${ }^{* *} P \leq 0.05$ is significant. ${ }^{* *} P \leq 0.001$ is particularly significant.

The results of rutting index are shown in Figure 9. It can be noticed from this figure that the rutting index gradually decreases with the temperature increasing. The rutting index increases with the PPA content increasing. It is observable that PPA can enhance the high-temperature behavior. Its rutting index decreases with bioasphalt content increasing.

When the PPA content is $2 \%$, the rutting index of the modified asphalt is much lower than that of the neat asphalt, as can be seen in Figure 9(a). As demonstrated in Figure 9(b), when PPA content is $4 \%$ and the bioasphalt contents are $10 \%$ and $12 \%$, the rutting indexes are the same as those of neat asphalt at $47.18^{\circ} \mathrm{C}$ and $55.57^{\circ} \mathrm{C}$. It can be seen in Figure 9(c) that the rutting index exceeds that of neat asphalt when the PPA content is $6 \%$, and the bioasphalt contents are $10 \%$ and $12 \%$. When the bioasphalt contents are $12 \%, 14 \%$, and $16 \%$, the rutting index is consistent with the neat asphalt when the temperatures are $47.07^{\circ} \mathrm{C}, 50.69^{\circ} \mathrm{C}$, and $53.29^{\circ} \mathrm{C}$, respectively. Figure 9 (d) illustrates that when PPA content is $8 \%$ and the bioasphalt content is $10 \%, 12 \%$, or $14 \%$, the rutting index exceeds that of neat asphalt. In summary, the rutting index increases with the PPA content increasing compared with neat asphalt.

When the content of PPA is $8 \%$ and the bioasphalt content is $10 \%$, the rutting index is $33.11 \mathrm{KPa}, 19.83 \mathrm{KPa}$, $12.34 \mathrm{KPa}, 7.79 \mathrm{KPa}$, or $4.9 \mathrm{KPa}$, respectively, at $46^{\circ} \mathrm{C}, 52^{\circ} \mathrm{C}$, $58^{\circ} \mathrm{C}, 64^{\circ} \mathrm{C}$, or $70^{\circ} \mathrm{C}$, respectively. The rutting index increases by $62.62 \%, 130.05 \%, 253.58 \%, 422.82 \%$, or $528.21 \%$, respectively. When PPA content is $8 \%$ and the content of bioasphalt is $14 \%$, the rutting index is $20.29 \mathrm{KPa}, 12.68 \mathrm{KPa}$, $7.34 \mathrm{KPa}, 4.21 \mathrm{KPa}$, or $2.65 \mathrm{KPa}$ at $46^{\circ} \mathrm{C}, 52^{\circ} \mathrm{C}, 58^{\circ} \mathrm{C}, 64^{\circ} \mathrm{C}$, or $70^{\circ} \mathrm{C}$, respectively. The rutting index increases by $-0.34 \%$, $47.1 \%, 110.32 \%, 182.55 \%$, or $239.74 \%$, respectively. This fact 


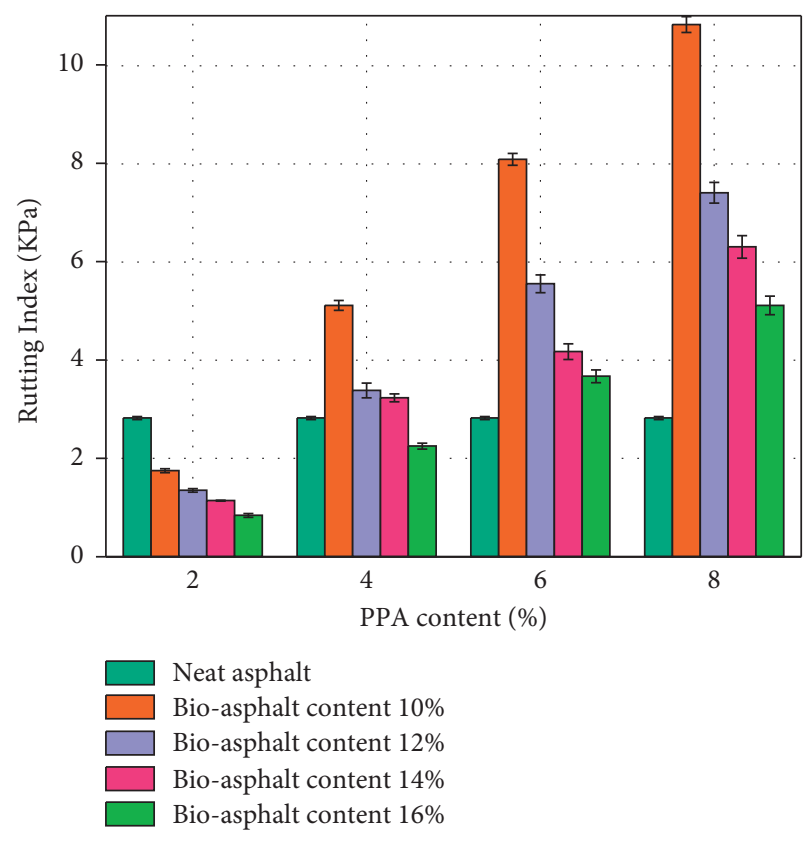

Figure 8: Rutting index $\left(60^{\circ} \mathrm{C}\right)$.

shows that the rutting index decreases with bioasphalt content increasing. The PPA improves the high-temperature properties of the corn stalk bioasphalt/PPA composite modified asphalt with the temperature rise.

3.2.2. BBR Test. Before the BBR test, the neat asphalt and corn stalk bioasphalt/PPA composite modified asphalt were subjected to RTFO-aging and PAV tests. The low-temperature behavior indexes of these asphalt samples were stiffness modulus and creep rate. They reflected the asphalt's temperature stress and relaxation ability. Generally, the smaller stiffness modulus and the higher creep rate can reflect outstanding crack resistance asphalt. The test results must meet the following requirements: the stiffness modulus should be less than $300 \mathrm{MPa}$, and the creep rate must be higher than 0.3 .

The BBR test was conducted on neat asphalt and the results are shown in Table 12. In this table, it can be analyzed that the creep rate of neat asphalt gradually decreases, and the stiffness modulus gradually increases as the temperature decreases. The neat asphalt creep rate is 0.29 at $-12^{\circ} \mathrm{C}$, which does not meet the specification requirements.

According to Table 13, the influence order of the factors on the creep rate $\left(-18^{\circ} \mathrm{C}\right)$ and stiffness modulus $\left(-18^{\circ} \mathrm{C}\right)$ is as follows: PPA content $>$ bioasphalt content $>$ shear time $>$ shear rate. As shown in Table 14, the PPA content shows a particularly significant impact on the creep rate of corn stalk bioasphalt/PPA composite modified asphalt. However, the PPA content has a significant impact on the stiffness modulus. The PPA influence on low-temperature behavior is significant.

Figure 10 shows that the creep rate is higher than 0.3 at $-18^{\circ} \mathrm{C}$. When the PPA content is $4 \%$, the creep rate has its maximum values. Figure 11 shows that the stiffness modulus values are all less than $300 \mathrm{MPa}$. It can be seen from
Figures 10 and11 that the low-temperature rheological properties gradually decrease with the PPA content increasing. In summary, the creep rate and stiffness modulus meet the requirements, indicating that the corn stalk bioasphalt/PPA composite modified asphalt has excellent lowtemperature behavior.

3.3. Fourier Transform Infrared Reflection (FTIR). To reveal the modification mechanism and functional group information, the neat asphalt, PPA modified neat asphalt, bioasphalt, blended asphalt, and corn stalk bioasphalt/PPA composite modified asphalt were subjected to FTIR test. The FTIR results are shown in Figures 12(a) and 12(b).

As presented in Figure 12(a), the absorption peaks at $2921 \mathrm{~cm}^{-1}$ and $2852 \mathrm{~cm}^{-1}$ increase by methylene $-\mathrm{CH} 2$ stretching vibration and alkane $\mathrm{C}-\mathrm{H}$ stretching vibration $[36,37]$. The peak at $1458 \mathrm{~cm}^{-1}$ represents methyl-assisted $\mathrm{C}-\mathrm{H}$ bending vibration [38]. The wavelength at $1374 \mathrm{~cm}^{-1}$ is caused by $-\mathrm{CH} 2$ [14]. The wavelengths at $811 \mathrm{~cm}^{-1}$ and $724 \mathrm{~cm}^{-1}$ are caused by C-H bending vibration and C-O-S symmetrical stretching on the benzene ring $[39,40]$.

As shown in Figure 12(a), the corn stalk bioasphalt/PPA composite modified asphalt has peaks of $1709 \mathrm{~cm}^{-1}$, $1150 \mathrm{~cm}^{-1}$, and $1002 \mathrm{~cm}^{-1}$, which are not present in the neat asphalt. The peaks at $1150 \mathrm{~cm}^{-1}$ and $1002 \mathrm{~cm}^{-1}$ appeared in PPA modified neat asphalt and corn stalk bioasphalt/PPA composite modified asphalt. However, these two peaks are not present in the blended asphalt, indicating that PPA causes the two of them. The absorption peak at $1150 \mathrm{~cm}^{-1}$ is produced by the $\mathrm{P}-\mathrm{O}$ single bond and $\mathrm{P}=\mathrm{O}$ double bond [41, 42]. The newly generated mixed absorption peak at $1002 \mathrm{~cm}^{-1}$, which is wide and large, is mainly caused by the antisymmetrical expansion and contraction of $\mathrm{P}-\mathrm{O}-\mathrm{C}$ in the phosphate $(\mathrm{RO})_{3} \mathrm{P}=\mathrm{O}$ formed after the reaction of PPA and asphalt [43]. Figure 12(b) shows that bioasphalt, blended asphalt, and corn stalk bioasphalt/PPA composite modified asphalt all have prominent peaks at $1709 \mathrm{~cm}^{-1}$ because of the fatty acid of $\mathrm{C}=\mathrm{O}$ stretching vibration in bioasphalt [6]. It indicated that the bioasphalt and the neat asphalt were physically blended.

3.4. Moisture Susceptibility Analysis. Some studies have shown that the bioasphalt moisture sensitivity is poor, and also this material affects the adhesion between aggregate and asphalt [14]. Asphalt spalled off from aggregate surface will affect the road durability. The moisture sensitivity of aggregate asphalt was evaluated by boiling water test. The aggregate in the boiling test was limestone. In order to evaluate the adhesion between asphalt and aggregate more accurately, this research work used Image-Pro software to measure the asphalt falling off from the aggregate surface after the boiling test and then the spalling rate was calculated, as shown in Figure 13. Taking the corn stalk bioasphalt/PPA composite modified asphalt (bioasphalt content of $10 \%$ and PPA content of $8 \%$ ) as an example, the moisture sensitivity comparison with neat asphalt is shown in Table 15. 


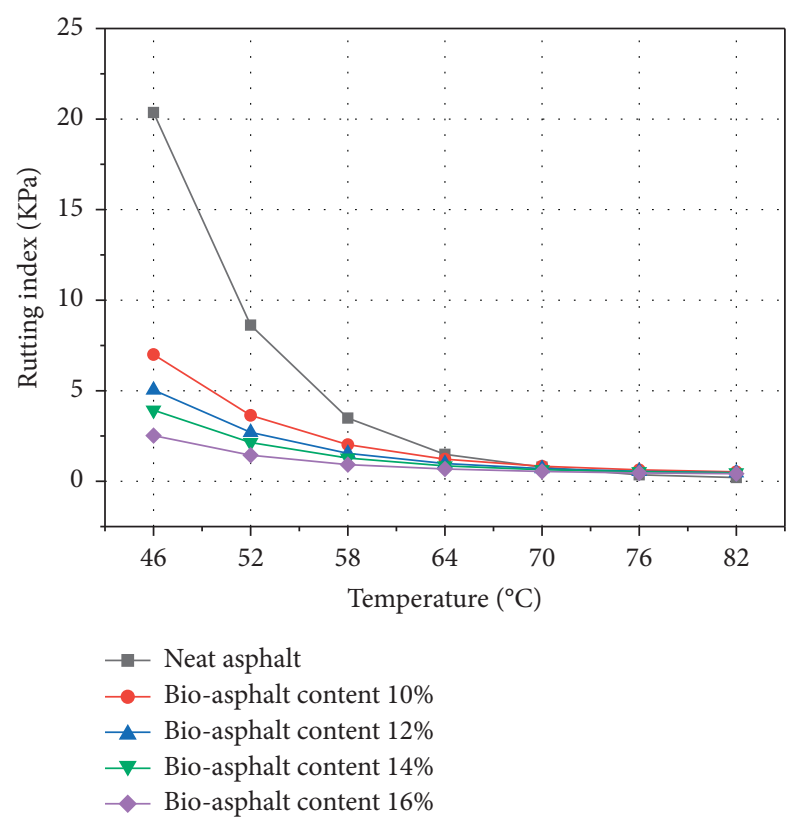

(a)

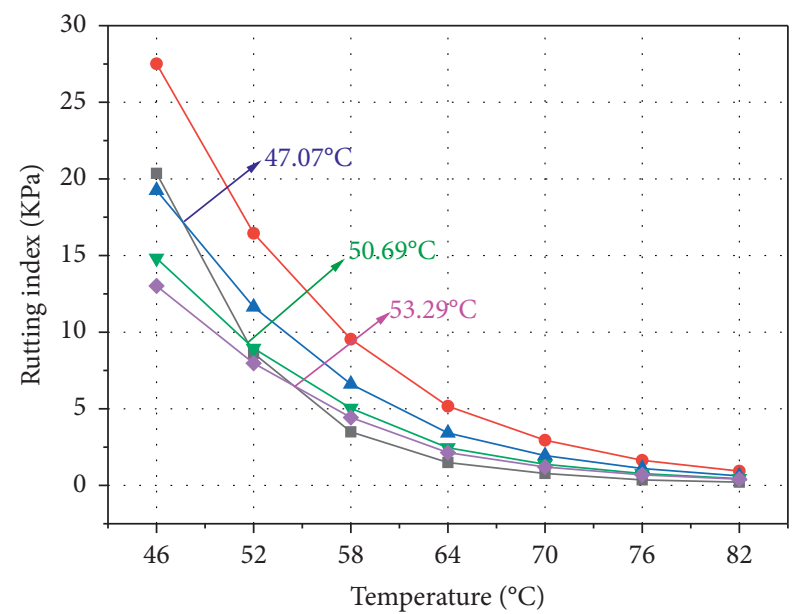

- - Neat asphalt

- Bio-asphalt content $10 \%$

- - Bio-asphalt content $12 \%$

$\rightarrow$ Bio-asphalt content $14 \%$

- Bio-asphalt content 16\%

(c)

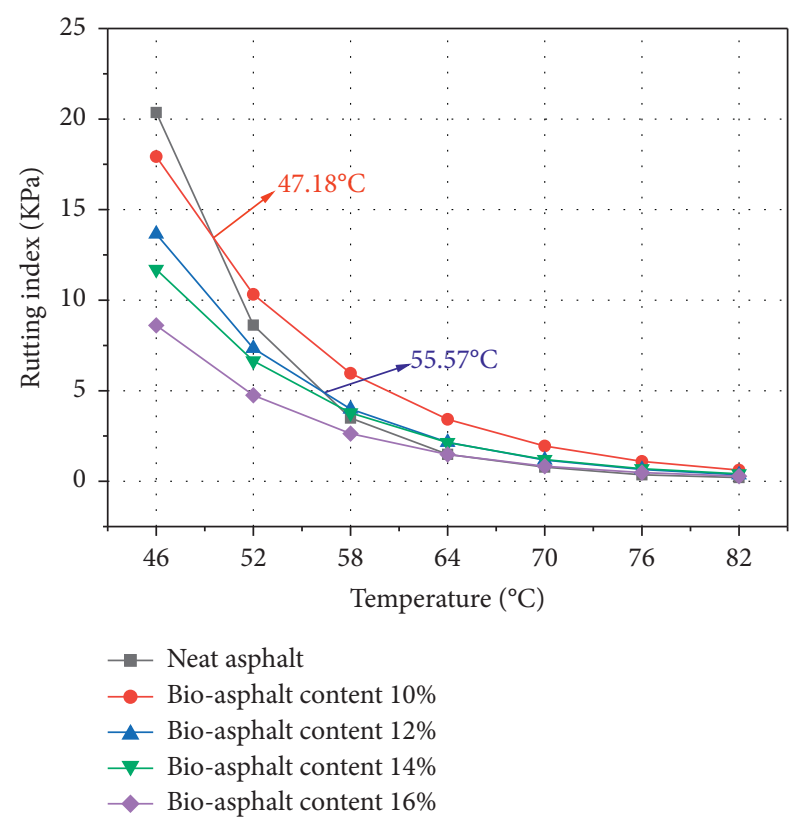

(b)

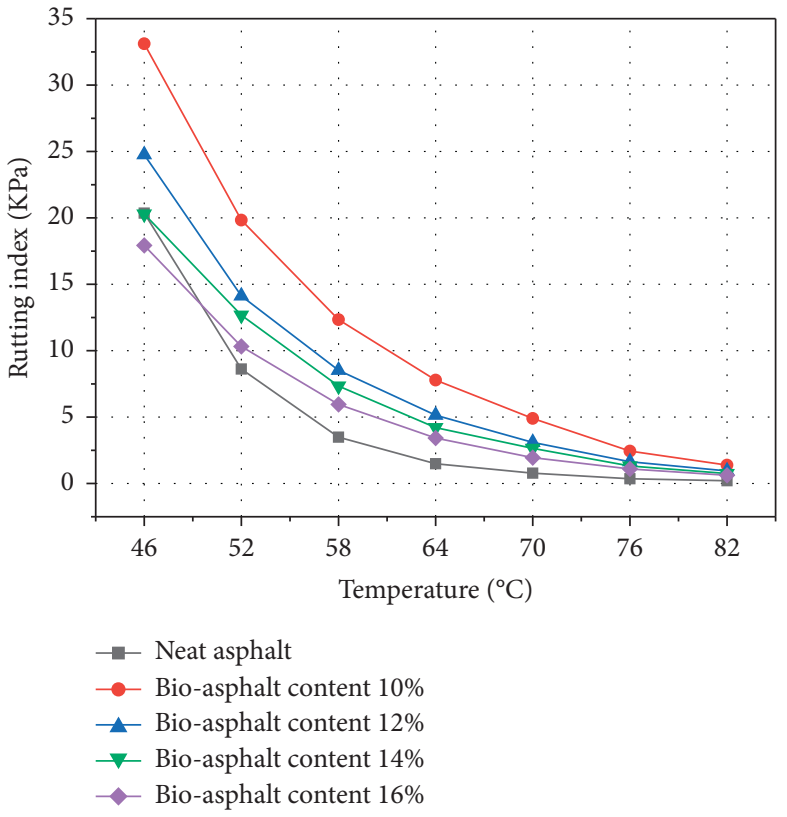

(d)

Figure 9: Rutting index: (a) PPA content of 2\%, (b) PPA content of 4\%, (c) PPA content of 6\%, and (d) PPA content of $8 \%$.

TABLE 12: BBR test results of neat asphalt.

\begin{tabular}{lcr}
\hline Index & Creep rate & Stiffness modulus (MPa) \\
\hline$-12^{\circ} \mathrm{C}$ & 0.29 & 80.2 \\
$-18^{\circ} \mathrm{C}$ & 0.24 & 249 \\
$-24^{\circ} \mathrm{C}$ & 0.18 & 370 \\
\hline
\end{tabular}

The results show that the neat asphalt's spalling rate is $20.3 \%$. However, the corn stalk bioasphalt/PPA composite modified asphalt's spalling rate is $23.6 \%$. The corn stalk
bioasphalt/PPA composite modified asphalt's moisture sensitivity is slightly higher than that of neat asphalt. Some studies have shown that the antistripping agent does not 
TABLE 13: Visual analysis of BBR results.

\begin{tabular}{llcccc}
\hline Index & Factor & PPA & Bioasphalt & Shear time & Shear rate \\
\hline \multirow{4}{*}{ Creep rate } & Average value 1 & 0.48 & 0.375 & 0.402 & 0.367 \\
& Average value 2 & 0.402 & 0.385 & 0.395 & 0.395 \\
& Average value 3 & 0.348 & 0.395 & 0.405 & 0.385 \\
& Average value 4 & 0.338 & 0.412 & 0.037 & 0.393 \\
\hline \multirow{5}{*}{ Stiffness modulus } & Range & 0.142 & 0.038 & 41.925 & 41.225 \\
& Average value 1 & 34.025 & 58.35 & 46.525 & 48.425 \\
& Average value 2 & 37.9 & 46.075 & 30.525 & 42.95 \\
& Average value 3 & 48.725 & 39.25 & 36.525 & 5.35 \\
\hline
\end{tabular}

TABLE 14: Analysis of variance of BBR.

\begin{tabular}{|c|c|c|c|c|c|c|c|}
\hline Index & Factor & Deviation sum of squares & Degrees of freedom & Mean-squared & $F$-value & $P$ value & Significance \\
\hline \multirow{4}{*}{ Creep rate } & $\mathrm{PPA}$ & 0.051 & 3 & 0.017 & 19.28 & 0.001 & **** \\
\hline & Bioasphalt & 0.003 & 3 & 0.001 & 0.21 & 0.89 & \\
\hline & Shear time & 0.004 & 3 & 0.001 & 0.24 & 0.87 & \\
\hline & Shear rate & 0.000 & 3 & 0.001 & 0.02 & 0.99 & \\
\hline \multirow{4}{*}{ Stiffness modulus } & PPA & 1585.72 & 3 & 528.57 & 4.07 & 0.03 & ** \\
\hline & Bioasphalt & 1137.03 & 3 & 379.01 & 2.26 & 0.13 & \\
\hline & Shear time & 226.19 & 3 & 75.4 & 0.310 & 0.82 & \\
\hline & Shear rate & 93.47 & 3 & 31.16 & 0.122 & 0.95 & \\
\hline
\end{tabular}

${ }^{*} P \leq 0.1$ is generally significant. ${ }^{* *} P \leq 0.05$ is significant. ${ }^{* * *} P \leq 0.001$ is particularly significant.

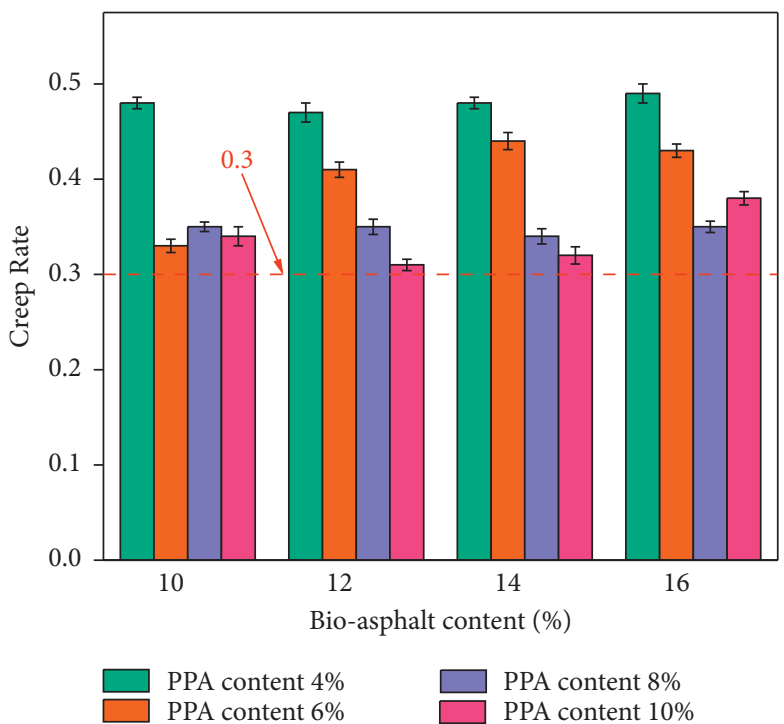

Figure 10: Creep rate $\left(-18^{\circ} \mathrm{C}\right)$.

affect the performance of asphalt $[44,45]$. A 0.3\% BHW511 antistripping agent was added to corn stalk bioasphalt/PPA composite modified asphalt to improve its adhesion. The result of the boiling water test is shown in Table 15. After adding BHW511, the corn stalk bioasphalt/PPA composite modified asphalt's spalling rate is $8.4 \%$, and the adhesion of asphalt is enhanced by $64.4 \%$. The BHW 511 reacts with the hydroxyl groups in the asphalt to generate hydrogen bonds and covalent bonds, which results in the asphalt and the aggregate being tightly packed together [46]. 


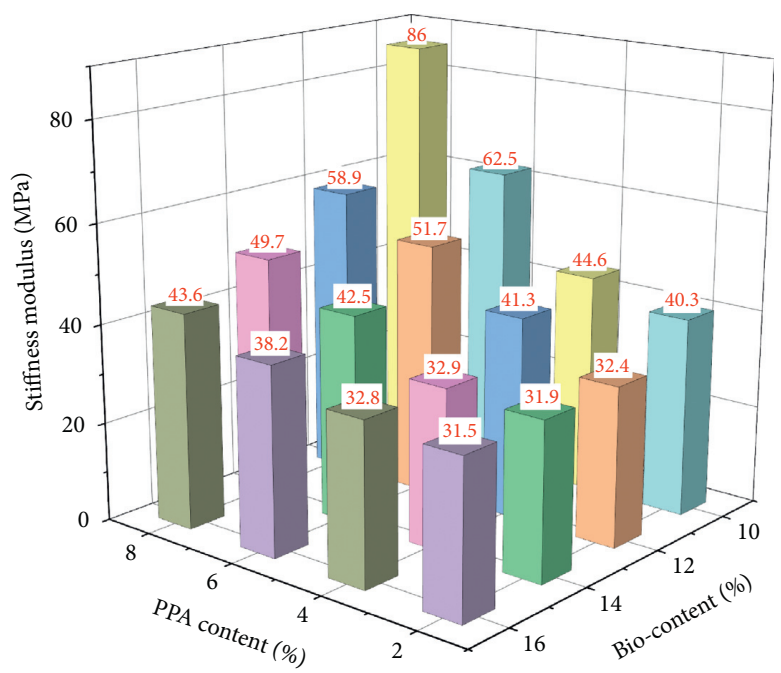

Figure 11: Stiffness modulus $\left(-18^{\circ} \mathrm{C}\right)$.
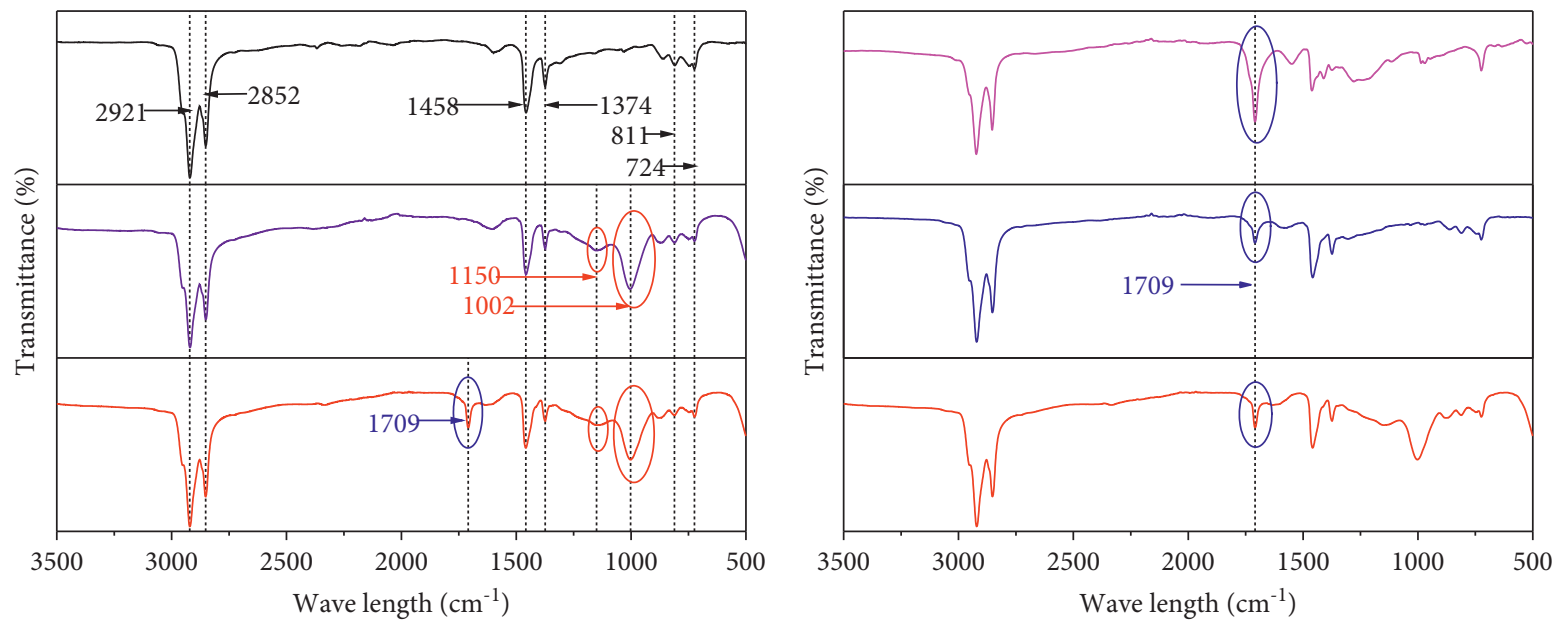

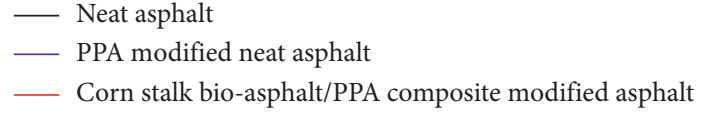

(a)

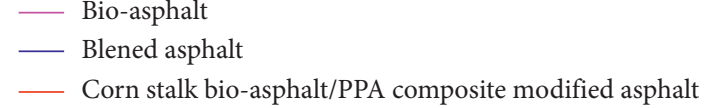

(b)

FIGURE 12: FTIR: (a) FTIR of neat asphalt, PPA modified neat asphalt, and corn stalk bioasphalt/PPA composite modified asphalt; (b) FTIR of bioasphalt, blended asphalt, and corn stalk bioasphalt/PPA composite modified asphalt.

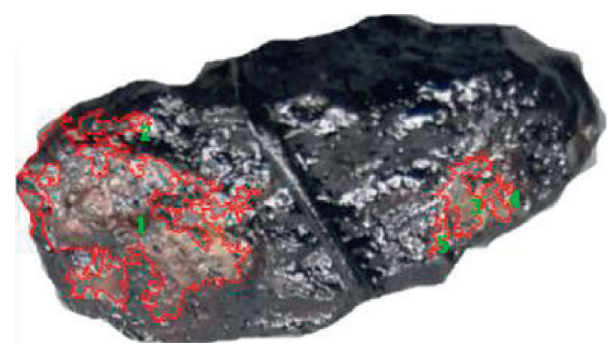

FIGURE 13: Asphalt spalling area. 
TABLE 15: Boiling water test results.

\begin{tabular}{|c|c|c|c|}
\hline Types of asphalt & Aggregate surface area & Asphalt spalling area & Spalling rate $(\%)$ \\
\hline Neat asphalt & 695842 & 196066 & 20.3 \\
\hline Corn stalk bioasphalt/PPA composite mo & 836874 & 197502 & 23.6 \\
\hline Corn stalk bioasphalt/PPA composite modified asphalt with BHW511 & 978566 & 82120 & 8.4 \\
\hline
\end{tabular}

\section{Conclusions}

This study evaluated corn stalk bioasphalt/PPA composite modified asphalt's performance on penetration, softening point, ductility, DSR test, and BBR test. FTIR test was undertaken to analyze the mechanism of modified asphalt. According to the test results, the following conclusions can be drawn:

(1) PPA content has the most remarkable impact on corn stalk bioasphalt/PPA composite modified asphalt performance. Penetration and ductility gradually decrease with PPA content increasing. However, the softening point and viscosity remarkably increased with PPA content increasing. Besides, the rutting index gradually increases when PPA content rises. The corn stalk bioasphalt/PPA composite modified asphalt can meet the requirements at $-18^{\circ} \mathrm{C}$. The corn stalk bioasphalt/PPA composite modified asphalt's moisture sensitivity is slightly higher than that of neat asphalt.

(2) Considering the low-temperature and high-temperature behavior, the optimal PPA content range is $6 \%-8 \%$, and the optimal bioasphalt content range is $10 \%-16 \%$. However, shear time and shear rate merely affect the performance of corn stalk bioasphalt/PPA composite modified asphalt.

(3) The bioasphalt added to the neat asphalt does not affect its chemical structure. It only causes physical modification. Nevertheless, PPA will produce new functional groups $\mathrm{P}-\mathrm{O}$ single bond, phosphate $(\mathrm{RO})_{3} \mathrm{P}=\mathrm{O}$, and $\mathrm{P}=\mathrm{O}$ double bond with asphalt, which results in the chemically blended binder.

(4) This work mainly studied the high-temperature and low-temperature behavior and did not conduct storage stability and aging tests. Future research works will focus on the aging behavior of bioasphalt and the mixture's fatigue characteristics.

\section{Data Availability}

The data used to support the findings of this study are included within the article.

\section{Conflicts of Interest}

The authors declare no conflicts of interest.

\section{Acknowledgments}

This project was supported by Key Technologies for Green and Intelligent Construction of Durable Expressway (Grant no. CYZX-JT-2020-05) and Science and Technology Progress and Innovation Project of Hunan Provincial Department of Transportation (Grant no. 201904, 202002).

\section{References}

[1] S. Lv, J. Yuan, X. Peng et al., "Performance and optimization of bio-oil/buton rock asphalt composite modified asphalt," Construction and Building Materials, vol. 264, Article ID 120235, 2020.

[2] J. Gao, H. Wang, Z. You, M. Mohd Hasan, Y. Lei, and M. Irfan, "Rheological behavior and sensitivity of wood-derived bio-oil modified asphalt binders," Applied Sciences, vol. 8, no. 6, p. 919, 2018.

[3] A. A. Cuadri, M. García-Morales, F. J. Navarro, and P. Partal, "Isocyanate-functionalized castor oil as a novel bitumen modifier," Chemical Engineering Science, vol. 97, pp. 320-327, 2013.

[4] L. Xia, D. Cao, H. Zhang, and Y. Guo, "Study on the classical and rheological properties of castor oil-polyurethane pre polymer (C-PU) modified asphalt," Construction and Building Materials, vol. 112, pp. 949-955, 2016.

[5] M. Zeng, J. Li, W. Zhu, and Y. Xia, "Laboratory evaluation on residue in castor oil production as rejuvenator for aged paving asphalt binder," Construction and Building Materials, vol. 193, pp. 276-285, 2018.

[6] T. Zhou, S. F. Kabir, L. Cao, H. Luan, Z. Dong, and E. H. Fini, "Comparing effects of physisorption and chemisorption of bio-oil onto rubber particles in asphalt," Journal of Cleaner Production, vol. 273, Article ID 123112, 2020.

[7] B. Tang, H. Zhu, and X. Cao, "Analysis on road performance of bio oil recycled asphalt binder," Journal of Chinese highway, vol. 32, pp. 207-214, 2019.

[8] J. Li, Study on Performance of Bio Asphalt Recycled Asphalt Binder, Hunan University, Changsha, China, 2018.

[9] Z. Yan and Q. Zhang, "Study on thermal regeneration aging SBS modified asphalt and mixture performance of bio oil regenerant," New building materials, vol. 47, pp. 83-87, 2020.

[10] M. Feng and X. Li, "Research progress of bio oil modified rubber asphalt and its mixture performance," Journal of Wuhan University of Technology, vol. 37, pp. 55-62, 2015, https://kns.cnki.net/ kcms/detail/detail.aspx?FileName=WHGY201502012\&DbName $=$ CJFQ2015.

[11] Z.-j. Dong, T. Zhou, H. Luan, R. C. Williams, P. Wang, and Z. Leng, "Composite modification mechanism of blended bioasphalt combining styrene-butadiene-styrene with crumb rubber: a sustainable and environmental-friendly solution for wastes," Journal of Cleaner Production, vol. 214, pp. 593-605, 2019.

[12] W. Tian, Study on Performance of Biological Asphalt Modified Asphalt Mixture, Hunan University, Changsha, China, 2017.

[13] M. Zeng, W. Tian, and Y. Zhu, "Study on performance of castor oil bio asphalt blended asphalt mixture," Journal of Hunan University, vol. 44, pp. 177-182, 2017.

[14] X. Jiang, Study on Property of Polymer Composite Bio-Asphalt, Chang'an University, Xi'an, China, 2018. 
[15] Y. Liu, Study on Mechanism and Performance Evaluation of SBS/Crumb Rubber Composite Modified Asphalt, Southeast University, Jiangsu, China, 2018.

[16] X. Jiang, P. Li, Z. Ding, L. Yang, and J. Zhao, "Investigations on viscosity and flow behavior of polyphosphoric acid (PPA) modified asphalt at high temperatures," Construction and Building Materials, vol. 228, Article ID 116610, 2019.

[17] P. Liang, M. Liang, W. Fan, Y. Zhang, C. Qian, and S. Ren, "Improving thermo-rheological behavior and compatibility of SBR modified asphalt by addition of polyphosphoric acid (PPA)," Construction and Building Materials, vol. 139, pp. 183-192, 2017.

[18] H. Liu, Z. Chen, Y. Wang, Z. Zhang, and P. Hao, "Effect of poly phosphoric acid (PPA) on creep response of base and polymer modified asphalt binders/mixtures at intermediatelow temperature," Construction and Building Materials, vol. 159, pp. 329-337, 2018.

[19] S. Alam and Z. Hossain, "Changes in fractional compositions of PPA and SBS modified asphalt binders," Construction and Building Materials, vol. 152, pp. 386-393, 2017.

[20] A. Ameli, E. Hassanzadeh Khabbaz, R. Babagoli, N. Norouzi, and K. Valipourian, "Evaluation of the effect of carbon nano tube on water damage resistance of Stone matrix asphalt mixtures containing polyphosphoric acid and styrene butadiene rubber," Construction and Building Materials, vol. 261, Article ID 119946, 2020.

[21] F. Xiao, S. Amirkhanian, H. Wang, and P. Hao, "Rheological property investigations for polymer and polyphosphoric acid modified asphalt binders at high temperatures," Construction and Building Materials, vol. 64, pp. 316-323, 2014.

[22] C. Qian, W. Fan, F. Ren, X. Lv, and B. Xing, "Influence of polyphosphoric acid (PPA) on properties of crumb rubber (CR) modified asphalt," Construction and Building Materials, vol. 227, Article ID 117094, 2019.

[23] J. Y. M. Nuñez, M. D. I. Domingos, and A. L. Faxina, "Susceptibility of low-density polyethylene and polyphosphoric acid-modified asphalt binders to rutting and fatigue cracking," Construction and Building Materials, vol. 73, pp. 509-514, 2014.

[24] C. Zhou, Study on Road Performance of Poly Phosphoric Acid Modified Asphalt, Hebei University of Technology, Tianjin, China, 2017.

[25] L. Yong, Research on Characteristics and Adhesion Evaluation Method of Bio-Oil Modified Asphalt, Doctor, Changan University, Xi'an, China, 2019.

[26] Z. Cao, M. Chen, J. Yu, and X. Han, "Preparation and characterization of active rejuvenated SBS modified bitumen for the sustainable development of high-grade asphalt pavement," Journal of Cleaner Production, vol. 273, Article ID 123012, 2020.

[27] F. Chen and R. Ma, "Experimental study on fatigue performance of full scale asphalt pavement," Chinese and foreign highways, vol. 40, pp. 42-46, 2020.

[28] Q. Lu, "Study of using waste oil modified asphalt to enhance the low temperature of asphalt," Highway Engineer, vol. 41, pp. 74-77, 2016.

[29] Z. Ding, J. Zhan, K. Jun, and P. Li, "Performance and mechanism analysis of bio-asphalt synthesized from sawdust liquefaction products," Journal of Guangxi University, vol. 43, pp. 1632-1639, 2018.

[30] L. Liu, Test Research on Evaluation Index of Asphalt Binder High Temperature, Changsha University of Science and Technology, Xi'an, China, 2005.
[31] B. F. Bowers, B. Huang, X. Shu, and B. C. Miller, "Investigation of reclaimed asphalt pavement blending efficiency through GPC and FTIR," Construction and Building Materials, vol. 50, pp. 517-523, 2014.

[32] X. Jia, B. Huang, B. F. Bowers, and S. Zhao, "Infrared spectra and rheological properties of asphalt cement containing waste engine oil residues," Construction and Building Materials, vol. 50, 2014.

[33] V. Catarina, P. Inês, R. Jorge, S. Artur, and S. Carlos, "Influence of polyphosphoric acid on the consistency and composition of formulated bitumen: standard characterization and NMR insights," Journal of analytical methods in chemistry, vol. 2016, Article ID 2915467, 2016.

[34] W. Cao, S. Liu, X. Cui, and Q. Shang, "Experimental study on polyphosphoric acid (PPA) modified asphalt binders," in Proceedings of the 3rd China International Conference on Asphalt Materials, pp. 51-58, Qingdao, 2009.

[35] A. Behnood and J. Olek, "Rheological properties of asphalt binders modified with styrene-butadiene-styrene (SBS), ground tire rubber (GTR), or polyphosphoric acid (PPA)," Construction and Building Materials, vol. 151, pp. 464-478, 2017.

[36] M. Liang, X. Xin, W. Fan, S. Ren, J. Shi, and H. Luo, "Thermostability and aging performance of modified asphalt with crumb rubber activated by microwave and TOR," Materials \& Design, vol. 127, pp. 84-96, 2017.

[37] J. Si, Y. Li, J. Wang, A. R. Niyigena, X. Yu, and R. Jiang, "Improving the compatibility of cold-mixed epoxy asphalt based on the epoxidized soybean oil," Construction and Building Materials, vol. 243, Article ID 118235, 2020.

[38] S. F. Kabir, M. Mousavi, and E. H. Fini, "Selective adsorption of bio-oils' molecules onto rubber surface and its effects on stability of rubberized asphalt," Journal of Cleaner Production, vol. 252, Article ID 119856, 2020.

[39] D. Sun, T. Lu, F. Xiao, X. Zhu, and G. Sun, "Formulation and aging resistance of modified bio-asphalt containing high percentage of waste cooking oil residues," Journal of Cleaner Production, vol. 161, pp. 1203-1214, 2017.

[40] K. Yan, Y. Peng, and L. You, "Use of tung oil as a rejuvenating agent in aged asphalt: laboratory evaluations," Construction and Building Materials, vol. 239, Article ID 117783, 2020.

[41] Q. Ma, X. Xin, W. Fan, M. Liang, and X. Wang, "Rheological properties and modification mechanism of PPA modified asphalt," Journal of China University of Petroleum, vol. 39, pp. 165-170, 2015.

[42] Q. Feng, Research on Rheological Properties and Road Performance of Polyphosphoric Acid Compound Modified Asphalt, Master, Changan University, Xi'an, China, 2019.

[43] M. Zhang, Research on Microstructure and Technical Performance of Polyphosphoric Acid Modified Asphalt, Changan University, Xi'an, China, 2012.

[44] M. Nazirizad, A. Kavussi, and A. Abdi, "Evaluation of the effects of anti-stripping agents on the performance of asphalt mixtures," Construction and Building Materials, vol. 84, pp. 348-353, 2015.

[45] Z. Chuanfeng, Q. Yong, L. Dan, Z. Ting, L. Xingyang, and Z. Shi, "Effects of anti-stripping agents on the microscopic strength of mineral aggregate contact surface," Construction and Building Materials, vol. 49, pp. 627-634, 2013.

[46] Y. Min, Study on the Preparation of Different Anti-stripping Agents and Their Water Stability Performance on Asphalt Mixtures, Hunan University, Master, Changsha, China, 2015. 